\title{
A Metalinguistic Awareness Test for ASL/English Bilingual Deaf Children: The TASLA-R*
}

\author{
Adonia K. Smith \\ ASL Rose Company, Silver Spring, USA \\ Jean F. Andrews \\ Lamar University, Beaumont, USA \\ Melissa Ausbrooks \\ Mississippi School for the Deaf, Jackson, USA \\ Mary Anne Gentry \\ Lamar University, Beaumont, USA \\ E. Lynn Jacobowitz \\ ASL Rose Company, Silver Spring, USA
}

\begin{abstract}
In this study, the researchers examined how deaf children could demonstrate their awareness of ASL by evaluating the correctness of ASL signs, sentences and discourse presented in stories in American Sign Language (ASL) signed by deaf native signers. To this end, a metalinguistic awareness test--the Test of American Sign Language-Receptive (TASLA-R), was created with eight short stories. The test consisted of 40 items presented in a multiple choice format test. Each of the 40 test items presented correct and incorrect statements about ASL formation using phonology, semantics, morphology, syntax and pragmatic aspects. One hundred and forty deaf children between the ages of 5 and 21 from four state schools for the deaf were administered the TASLA-R. Significant findings were as follows: 1) As the children got older, there was an increase in their ASL metalinguistic awareness and ability to identify incorrect ASL structures; 2) the deaf children of deaf parents group outperformed the deaf children of hearing group on the TASLA-R; 3) comparisons of TASLA-R scores between the junior high group and the high school were not significant; 4) scores on the TASLA-R showed moderate correlation to the English language, vocabulary and reading comprehension subtests on the Stanford Achievement test, $9^{\text {th }}$ Hearing Impaired edition. These findings were discussed in relation to Ellen Bialystok's (2001) theories of metalinguistic uses of language in cognition and language development and in relation to the learning of ASL of bilingual deaf children.
\end{abstract}

Index Terms-deaf, American Sign Language (ASL), ASL assessment, bilingual, metalinguistic awareness, reading, early childhood

"As they enter the school years, children's words become increasingly complex and interconnected, and children also gain a new kind of knowledge: metalinguistic awareness. This new ability makes it possible for them to think about their language, understand what words are, and even define them." (Berko-Gleason, 1997, p. 4)

\section{INTRODUCTION}

Hearing teachers frequently encounter a young deaf child who corrects their signs. Apart from the humbling nature of the event, what the deaf child is exhibiting is metalinguistic use of language. Indeed, when the hearing teacher's signs do not match the deaf child's internalized American Sign Language (ASL) knowledge, the deaf student uses her internal knowledge of ASL, senses it does not match, and attends to the incorrectness of the teacher's sign production, grammar, and discourse. Such metalinguistic awareness is a cognitive and linguistic ability that allows deaf children think about their language and judge the correctness of signs around them.

As such, metalinguistic uses of language provide children with the tools to think about and use language structures to increase their cognitive and linguistic development (Bialystok, 2001; 1991). The purpose of this study was to examine how deaf children could evaluate the correctness of ASL signs, sentences, and discourse when presented entertaining

\footnotetext{
* This project was supported by Department of Education (OSERS) Student-Initiated Competition (Grant \#H324BO20084), Training Doctoral Level Leaders in Deaf Education (Grant \#H325E980050) and William C. Stokoe Scholarship under the National Association of the Deaf. This paper was based in part on the first author's doctoral dissertation completed at Lamar University.
} 
stories in ASL by native deaf signers. A test of metalinguistic knowledge--the Test of American Sign LanguageReceptive (TASLA-R) was constructed and presented to 140 deaf children in 4 state schools for the deaf to examine their metalinguistic knowledge.

This study addressed three questions:

1. Was there a developmental pattern of TASLA-R scores across different age groups, different grade levels and with parents of different hearing status?

2. Was there a relationship between students' TASLA-R scores and other background language-learning variables?

3. Was there a relationship between TASLA-R scores and English achievement as designated by three subtests on the Stanford Achievement Test- $9^{\text {th }}$ edition?

\section{REVIEW OF THE LITERATURE}

\section{Defining the Construct-Metalinguistic Uses of Language}

In the early 1970's at about the same time Ursula Bellugi, a developmental psycholinguist, and Edward Klima, a linguist, were describing American Sign Language (ASL) milestones of deaf children of deaf parents and discovering that ASL was processed in the left part of the brain (Klima \& Bellugi, 1979), the cognitive construct, metalinguistic awareness came into focus in the child language literature. Metalinguistic awareness was first applied to various cognitive functions such as metacognition and metamemory (Bialystok, 2001).

Bialystok (2001) defined the construct of metalinguistics according to three different aspects: knowledge, ability and awareness. She differentiates each as having different cognitive processing demands. Metalinguistic knowledge refers to having knowledge of the general principles of language (ie. word ordering, morphological patterns). Bialystok claimed that metalinguistic knowledge is related to understanding that there are "universal templates of language structures" such as similar categories of nouns, verbs, and adjectives, adverbs with which children learn to facilitate their language acquisition (Bialystok, 2001).

The second context proposed by Bialystok (2001), that of metalinguistic ability refers to a skill where the child can use knowledge about language as distinct from the ability to use language for communication (Bialystok, 2001). And in the third context, metalinguistic awareness refers to the child's attention to language forms and their ability to make abstract representations of language described below.

Metalinguistic awareness for hearing monolingual children can encompass a variety of skills, such as judging grammaticality in sentences and having the ability to correct them (Cairns, Schlisselerg, Waltzman \& McDaniel, (2006). Other researchers have focused on the hearing children's ability to develop phonological awareness through rhyming, alliteration, blending and elision as they begin to learn to read (Adams, 1990). As children progress in their grades at school, they are required to attend to more forms of their language. For example, they are required to write a sentence or paragraph, tell a story, answer comprehension questions, explain how things work, and give definitions of words (Snow, 1990).

For a signing deaf child, metalinguistic awareness, knowledge and abilities can refer to their ability to determine if a sign is made correctly with the correct handshape, movement of orientation. A deaf child may comment that a signing adult (such as a parent or teacher) uses "hearing sign." What they may not be able to articulate but intuitively know is that the hearing person is making signs that are more like the English language and that some signs are even being made inaccurately. This demonstrates their metalingusitic awareness, knowledge and abilities as they are focusing on the form of the language, and not just the communication aspect. This topic is virtually unexplored in the literature with signing deaf children.

\section{Metalinguistic Awareness, Cognition and Bilingualism}

Both Vygotsky (1962) and Leopold (1939-49) (cited in Bialystok, 2001) hypothesized that bilingual children could manipulate language symbols earlier in life than monolingual children and this played a part in their language knowledge as well as their mental or cognitive, social and language development (Grojean, 2010; 2008; Bialystok, 2001; 1991).

Other researchers have also noted how metalinguisitic uses of language played a part in the developing the "mental mind" of the child and point to added advantages (Bialystok, 2001). For instance, Grosjean (2010; 2008) summarizes studies that report on cognitive advantages of bilingualism on concept formation, creativity, and Piagetian conservation tasks, and visual-spatial abilities, classification skills and analogy reasoning. Furthermore, executive functioning was found to be enhanced when children are bilingual (Bialystok, 2001). Executive functioning refers to the child mastering the ability to control attention, inhibit distraction, monitor a set of stimuli, expand working memory, and shift between tasks. Studies show that bilingual children perform these tasks better than monolingual children (Bialystok, 2001; Diaz \& Klinger, 1991).

Bilingual children are also believed to have more opportunities to develop both awareness of and control of language processing to a greater extent than monolingual children, particularly in the areas of codeswitching from one language to another as well as during problem solving tasks (Bialystok, 2001; 1991).

\section{Assessing the Metalinguistic Construct in ASL}

The impetus for this study to construct a metalinguistic test in ASL arose from the lack of such a tool available for teachers. For the most part, the documentation of ASL on the deaf child's Individual Educational Plans (IEPs) has been 
in the form of checklists or descriptions (French, 1999). Most diagnosticians, speech-language pathologists as well as teachers don't know how to or what to assess with ASL, nor have they had any training in ASL linguistics or ASL assessment (Gonzales, Covell \& Andrews, 2005). However, there have been attempts to develop ASL assessments for the classroom and the research laboratory.

The most comprehensive review of signed language assessments used in different countries including the U.S., is found on website created by Tobias Haug (1999). Haug's website underscores that the majority of these tests do not have psychometric properties, nor are they commercially available or easy for teachers and other non-linguists to administer, score and interpret.

\section{Metalinguistic Uses of L1 And L2 Learners}

It has been debated in the field whether deaf children's metalinguistic awareness in ASL will assist them in their learning of English literacy, given that both languages are fundamentally different in structure and in modality (Valli \& Lucas, 2000). ASL is a visual-spatial language that codes grammar simultaneously in signs, facial expressions, space and body movements, whereas English is an auditory linear-sequential language (Valli \& Lucas, 2000). Evidence from studies of deaf adults show that ASL proficiency assists them in reading English (Freel, Clark, Anderson, Gilbert, Musyoka \& Hauser, 2011; Ausbrooks, 2007). For young deaf children, some argue that ASL can be directly bridged or mapped onto the learning of English print using codeswitching (Andrews \& Rusher, 2010), fingerspelling (Baker, 2010; Haptonstall-Nykaza \& Schick, 2007) and bridging strategies (Ausbrooks-Rusher, Schimmel \& Edwards, 2012). Others counterclaim that an English-based mediating system such as Cued Speech, manual codes of English or Visual Phonics must be used to link meaning with print (Mayer \& Wells, 1996; see reviews in Trezek, Wang \& Paul, 2010). Further it is not clear from these studies that the users of English-based mediating systems are also including ASL lexical signs and structures in their interventions in order to lay down conceptual meanings prior to using their English systems, thus adding confounding factors to their studies. Clearly more empirical studies are needed to fully describe the effectiveness of these interventions as well as measure their effectiveness.

\section{METHOD}

\section{Participants}

Participants were 140 deaf students between the ages of five and twenty-one who were recruited by contacting superintendents from four residential schools for the deaf. All were prelingually and severely to profoundly deaf and were enrolled in one of four state schools for the deaf. Deaf students' ages in high school often exceed hearing youths' ages (14 to 18 years). Deaf youths typically need more time to catch up due to their hearing loss and being in a language-deprived home environment. Consequently, deaf youths are entitled to a free and appropriate education until their 21 st birthday.

In this study, language-learning background variables related to individual characteristics (i.e., age, ethnicity), family characteristics (i.e., parent hearing status, number of deaf siblings), and clinical variables (i.e. hearing loss, etiology) were collected, as these variables have been shown to affect language learning in the deaf school-age population (Andrews, Leigh \& Weiner, 2004; Quigley \& Kretchmer, 1982). See tables 1, 2, and 3. 
TABLE 1

INDIVIDUAL CHARACTERISTICS OF 140 STUDENTS WHO TOOK THE TASLA-R (AGE, GENDER, IQ, ETHNICITY, EDUCATIONAL PLACEMENT, AND SCHOOL DESIGNATED BY GEOGRAPHIC LOCATION

\begin{tabular}{lll}
\hline Variable & N & Percent \\
\hline Age & & \\
$5-9$ yrs & 29 & 21 \\
$10-14$ yrs & 60 & 43 \\
$15-21$ yrs & 51 & 36 \\
Total & 140 & 100 \\
Gender & & \\
Males & 66 & 47 \\
Females & 74 & 53 \\
Total & 140 & 100 \\
IQ & & \\
80 or below & 10 & 10 \\
Average (81-115) & 69 & 71 \\
Above average (116+) & 18 & 19 \\
Total & 97 & 100 \\
Ethnicity & & \\
White & 98 & 70.0 \\
African-American & 22 & 15.7 \\
Hispanic & 16 & 11.5 \\
Asian & 2 & 1.4 \\
Biracial & 2 & 1.4 \\
Total & 140 & 100 \\
School Designated by & & \\
Location & 32 & 22.8 \\
South & 33 & 23.6 \\
Midwest 1 & 43 & 30.7 \\
Midwest 2 & 32 & 22.9 \\
West & 140 & 100 \\
Total & & \\
& &
\end{tabular}

TABLE 2

FAMILY CHARACTERISTICS VARIABLES

\begin{tabular}{lll}
\hline Variable & N & Percent \\
\hline Parents Hearing Status & & \\
Hearing Parents & 78 & 55.7 \\
At Least One Deaf Parent & 61 & 43.6 \\
Total & 140 & 100 \\
Presence of Deaf Siblings & 56 & \\
Yes & 77 & 42.1 \\
No & 133 & 57.8 \\
Total & & 100 \\
Mother's ASL Skills & 6 & \\
None & 29 & 4.5 \\
Poor & 14 & 21.7 \\
Fair & 25 & 10.5 \\
Good & 60 & 18.6 \\
Outstanding & 134 & 44.7 \\
Total & & 100 \\
Father's ASL Skills & 12 & \\
None & 33 & 9.1 \\
Poor & 16 & 24.9 \\
Fair & 11 & 12.0 \\
Good & 61 & 8.2 \\
Outstanding & 133 & 45.8 \\
Total & & 100 \\
& &
\end{tabular}

${ }^{1}$ The IQ tested used with deaf children in this study and reported by school were the following: WISC-III ( $\left.\mathrm{n}=26\right)$, WISC-IV ( $\mathrm{n}=6$ ), TONI-2 ( $\mathrm{n}=8$ ), WAIS-III ( $n=4)$, UNIT ( $n=16)$, WIAT $(n=1)$, Leiter-R ( $n=3)$, WPPSI $(n=2)$, TONI-3 ( $n=7)$, C-TONI $(n=1)$, WISC $(n=4)$, TONI $(n=1)$. 
TABLE 3

DEAFNESS CLINICAL VARIABLE

\begin{tabular}{lcc}
\hline Variable & N & Percent \\
\hline Hearing Loss (in better ear) & 72 & 59.0 \\
90+dB (profound) & 29 & 23.8 \\
$71-90$ dB (severe) & 21 & 17.2 \\
$43-70$ dB (moderate) & 122 & 100 \\
Total & & \\
Etiology & 37 & 28.9 \\
Unknown & 31 & 24.2 \\
Other $^{2}$ & 60 & 46.9 \\
Genetic/hereditary & 128 & 100 \\
Total & Note: totals do not equal 140 in every category because of lack of response.
\end{tabular}

\section{Instrument: Description and Development of the TASLA-R}

The Test of American Sign Language-Receptive (TASLA-R), developed by Smith (2007) for this study, is a diagnostic tool designed to be used by teachers to assess the receptive metalinguistic awareness of deaf students, ages five to twenty-one. The TASLA-R was made up of eight stories signed by eight different native ASL storytellers. The ASL storysigners were from a diverse group of deaf native signers from different ethnic backgrounds (i.e., AfricanAmerican, Asian-American, Hispanic-American) (Smith, 2007). The eight stories incorporated elements of both ASL literature and Deaf literature in which the storytellers used ASL poetry, jokes, and narratives that play with the handshapes, the use of space and other linguistic structures of ASL (Peters, 2000; Valli \& Lucas, 2000).

The structure and administration of the TASLA-R was similar to other language tests that present stories or paragraphs, then require students to respond to questions in a multiple choice format. A similar structure is found in the vocabulary, reading comprehension and language subtests of the Stanford Achievement Test $-9^{\text {th }}$ edition. For example, the TASLA-R required the student to "attend" to a story in ASL on a DVD, then answer questions presented in ASL and respond to a set of four choices that could be presented in an ASL movie clip or also or in a picture format. After a warm-up practice story to ensure the students understood the directions of the test, the eight stories were presented to each student either individually or in a group setting. After viewing each story, the students answered 5 questions for a total of 40 questions ( 8 stories X 5 questions $=40$ items). The test took approximately 90 minutes to complete. The TASLA-R scores yields one total score related to the student's metalinguistic functioning in ASL across five domains: phonology, morphology, semantics, syntax, and pragmatics. See Appendix 1 and 2.

The initial development and pilot testing of the TASLA-R was conducted in 2004 as part of the first author's doctoral dissertation (Smith, 2007). The test item questions were developed for each story that corresponded to five aspects of ASL linguistic structure: phonology, morphology, semantics, syntax, and pragmatics. Thus, the test assessed the students' metalinguistic abilities about the formation of ASL signs and ASL structures. For example, one test item showed the students an ASL handshape from a sign in the story. In the multiple choice items, the student had to choose which sign had a similar handshape. Other test items were created which tapped into the students' linguistic knowledge of ASL after having seen the complete story.

The 40 test items were created using the authors extensive background teaching reading to signing deaf children, the first author's native fluency in ASL, the second, third and fourth author's experiences of having learned ASL as a second language for the past 30 years, and the fifth author who spent over 30 years teaching ASL as a second language. Also enlisted were a panel consisting of five experts and a panel of 10 deaf graduate students studying the literature on ASL linguistics and ASL language learning of deaf students.

After the items were created, the students were presented to a focus group--a panel of experts consisting of a psychologist with experience in language and psychological testing, two ASL linguists and two experienced teachers of deaf students. The panel provided commentary on the difficulty of the items and the difficulty \& appropriateness of the distracters on the test items. For example, some items and distracters on the test items were considered vague, confusing, too easy or too difficult, so changes were made. Next the eight stories were presented to a panel of 10 native Deaf signing graduate students who were students in the Masters Degree program in Deaf Studies/Deaf Education. The panel arranged the stories in order, from simplest to more complex.

The final version of the TASLA-R, both stories and test questions, was placed on a DVD. This enabled the examiner to show the tests to the Deaf participants using a computer and an LCD for single-subject as well as group administration. See Appendixes 1,2 and 3.

TASLA-R Psychometric Characteristics

A spread of scores, discriminating power, and high internal consistency are features that demonstrate the reliability of test scores achieved by students (Gronlund, 1981). The mean was 23.33, and the standard deviation of the 140 subjects' scores was 6.748 .

Internal Consistency

\footnotetext{
${ }^{2}$ Other categories of etiologies included the following: Meningitis, maternal drug use, cytomegalovirus, rubella, high fever, lack of oxygen, prematurity.
} 
The Cronbach's Alpha estimates the reliability test whether the items in the tests are homogeneous - that is, whether each test item measures the same quality or characteristic as every other. For the 140 deaf subjects, the Cronbach Alpha was .724, thus showing a moderate degree of internal consistency.

\section{Content Validity}

Content validity is important when the researcher aims to describe how an individual performs on a domain of tasks that the test is supposed to represent (Gronlund, 1981). In the construction of the test, it was decided to ask questions related to the five parameters of ASL as designed by ASL linguists (Valli \& Lucas, 2000). In other words, in the forty item TASLA - R, five items related to phonology were asked, five to semantics, five to morphology, five to syntax, and five to pragmatics, thus ensuring that a representative sample of the domains of ASL tasks were considered in the test construction.

The researcher also established content validity by asking a panel of ASL linguists, ASL/English bilingual educators, teachers of ASL as a second language, a deaf interpreter-trainer, and a psychologist who reviewed and commented on the TASLA - R test items. Two deaf ASL linguists were involved in all steps of the test development and provided comments on stories, questions and answers from earlier to later versions. Revisions were made based on the recommendations of the ASL linguists, ASL/English bilingual educators, and the interpreter-trainer.

\section{Criterion Validity}

Criterion validity was determined using a test of American Sign Language developed for research purposes by Dr. Ursula Bellugi and her colleagues at the Salk Institute (Poizner, Klima \& Bellugi, 2000). The researcher selected ten items from the Bellugi test. This was a picture test in which the deaf subject was signed a sentence, then asked to pick out the right answer from four pictures in a multiple-choice format. One ASL structure tested was decomposition. The deaf subjects had to select a similar handshape to the sign they were presented. For instance, the subject was signed NAME. The five pictures were a) an egg, b) an onion, c) a dog, d) a ship. The correct answer was a) egg. The signs $\mathrm{NAME}^{3}$ and EGG share the same handshape. Two different items tested for decomposition or identification of a similar handshape.

The other ASL structures included noun-verb comprehension, nominal establishment, verb agreement with pictures, and verb agreement without pictures but with shifting framework. For instance, the deaf subject is shown a picture of a girl in the signer's space (left) and a boy in the signer's space (right). The directional verb, HIT (from right to left) shows which person is hitting the other. The deaf participant can choose, a. a picture of a boy hitting the girl or a picture of a girl hitting the boy. The Pearson Product Moment Correlation of the TASLA - R and the Bellugi ASL test was $.515(\mathrm{p}<.01)$, showing a moderate but statistically significant correlation.

\section{Item Level of Difficulty}

According to Gronlund (1981), we can estimate a desirable average difficulty for a domain-referenced test by taking the point midway between the expected chance score and the maximum possible score. Thus, for a test like the TASLA - R, which is a forty-item test, the average difficulty would be 30 (midway between 20 and 40). The mean score of the total group of deaf participants was 23.33 , and the standard deviation was 6.748 . Given that a perfect score would be 40 points, it can be determined that the TASLA - R has a reasonably average level of difficulty. In other words, the average score is between 20 and 40, showing that the TASLA - R was able to discriminate between high and low achievers in ASL. See Appendix 3.

\section{Item Order of Difficulty by Test Item}

The researcher demonstrates the forty test items in order of difficulty as computed based on the students' responses. The test item number, the number of students who scored the item correctly (raw score and percent), the name of the story, and the ASL structure were also calculated.

\section{Item Order of Difficulty by Story and ASL Structures}

The number of students who answered correctly each of the test items as categorized by type of ASL structure (e.g., phonology, morphology, semantics, syntax, and pragmatics) is presented below. The highlighted numbers show that less than fifty percent of the students $(n=123$ students) could answer that particular item correctly, thus showing the difficulty of these items across the areas of phonology, morphology, syntax, and pragmatics. See Appendix 3.

\section{TASLA-R Instructions}

Deaf student participants were enrolled in state school for the Deaf that used an ASL/English bilingual philosophy as their language policy. The examiner (the first author) for the TASLA-R is a native deaf person who is fluent in ASL. The examiner met with the school personnel and was directed to the files of the students where she collected the background variables and entered them on a spreadsheet. She then met with the students, either individually or in a group.

The students were first shown the first practice warm-up story to ensure they understood the directions. The examiner then walked them through five practice test items, making sure the students understood what was expected of them. After they viewed each question, they entered their responses (A, B, C, D. E) on a paper in front of them. (Efforts to computerize the whole test were not accomplished during this administration of the test due to technical difficulties.)

\footnotetext{
${ }^{3}$ We use the convention of capital letters to designate a manual sign.
} 
After completing the practice story and five items and when the experimenter was sure the students understood the directions, then the eight stories with 40 test items were then administered.

Procedures and Scoring

The TASLA-R was administered to all 140 participants individually or in groups of three to five students, following the instructions outlined above. The students' responses were scored on paper, and then their score (1 to 40) was entered into an SPSS database for analysis.

\section{RESUlTS}

The data was analyzed by making comparisons of judgment scores for 1) all age groups, across parent hearing status and grade levels, 2) the number of correct judgments on the TASLA-R taking into account other background languagelearning variables, and 3) the number of correct judgment scores compared to performance of the students' on the Stanford Achievement Test (SAT-HI 9) on three subtests: reading vocabulary, reading comprehension and language subtests.

Research Question \#1: Is there a relationship with TASLA-R scores and age when tested, grade level, parent hearing status and the five aspects of ASL linguistics?

Comparison of TASLA-R Judgment Scores Across Ages: A Development Picture

Table 4 presents mean scores for each age of student and total score on the TASLA-R. Recall that scores ranged from 0 to 40 on the complete TASLA-R. Examination of the data in table 4 reveals a difference overall on the TASLA-R performance across the age groups. See Figure 1 to see this relationship graphically displayed. As the deaf bilingual child grew older, he or she increased their metalinguistic knowledge in ASL. There appears to be some dips in the sixto-ten age range.

TABLE 4:

MEANS AND STANDARD DEVIATIONS OF TASLA-R JUdGMENT SCORES ACROSS AGE IN YEARS WHEN TEST WAS TAKEN (N=140)

\begin{tabular}{llll}
\hline Age in Years & Mean & N & Standard Deviation \\
\hline 5 & 10.00 & 1 & \\
6 & 21.33 & 3 & 6.51 \\
7 & 17.78 & 9 & 6.66 \\
8 & 14.75 & 4 & 6.60 \\
9 & 20.25 & 12 & 7.59 \\
10 & 19.88 & 16 & 6.78 \\
11 & 22.92 & 12 & 6.21 \\
12 & 23.87 & 8 & 4.08 \\
13 & 25.33 & 15 & 4.88 \\
14 & 24.44 & 9 & 5.96 \\
15 & 24.5 & 10 & 6.39 \\
16 & 26.6 & 10 & 6.38 \\
17 & 30.67 & 3 & 1.15 \\
18 & 27.52 & 21 & 5.12 \\
19 & 21.33 & 6 & 7.50 \\
20 & 23.00 & 1 & \\
\hline
\end{tabular}

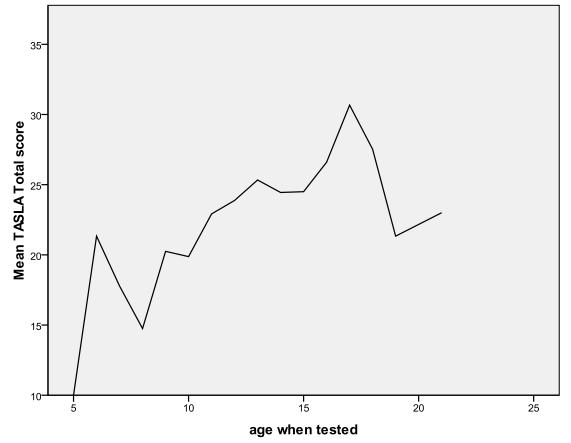

Figure 1: Mean TASLA-R Scores of 140 students and Age in Years When Tested (range from 5 years to 21 years)

A one-way ANOVA was used to test the differences in TASLA-R scores among the age levels. TASLA-R performance differed significantly across the age levels: $\mathrm{F}(13,137)=3.402$, $\mathrm{p}<.05$. Tukey post-hoc comparisons of the different age groups indicated that the 18 year-olds $(\mathrm{M}=27.2,95 \%$ CI $[25.19-29.86]), \mathrm{p}<.05$ scored significantly higher than the 7 year olds $(\mathrm{M}=17.78,95 \% \mathrm{CI}[12.65-22.90])$, the 8 year olds $[\mathrm{M}=14.74,95 \% \mathrm{CI} 4.25-25.25])$, and the 10 year olds $[\mathrm{M}=19.88,95 \% \mathrm{CI}[16.26-23.49])$. The 17 year olds $(\mathrm{M}=30.67,95 \% \mathrm{CI}$ [27.80-33.54]) scored significantly higher than the 8 year olds $(\mathrm{M}=14.75,95 \% \mathrm{CI}[4.25-25.25])$. Other age group comparisons showed differences in mean scores but the differences did not reach statistical significance.

Comparison of TASLA-R Scores Across Age, Grade Level and Parent Hearing Status 
Table 5 displays the average number of correct judgments across the ages of the students taking the TASLA-R examining the parent hearing status (deaf and hearing). As expected because of early and more language exposure to ASL, the deaf children of deaf parents group outperformed the deaf children of hearing parents group. The students with deaf parents demonstrated increased metalinguistic knowledge compared to the deaf children of hearing parents. See this relationship graphically displayed in figure 2.

TABLE 5:

TASLA-R TOTAL SCORES AND PARENTS HEARING STATUS ( $=140)$

\begin{tabular}{|c|c|c|c|}
\hline Parent Hearing Status & Mean & $\mathbf{N}$ & $\begin{array}{l}\text { Standard } \\
\text { Deviation }\end{array}$ \\
\hline $\begin{array}{l}\text { Group 1: At least one Deaf } \\
\text { Parent }\end{array}$ & 26.16 & 62 & 5.865 \\
\hline $\begin{array}{l}\text { Group 2: Two Hearing } \\
\text { Parents }\end{array}$ & 20.90 & 78 & 6.605 \\
\hline Total & 23.23 & 140 & 6.793 \\
\hline
\end{tabular}

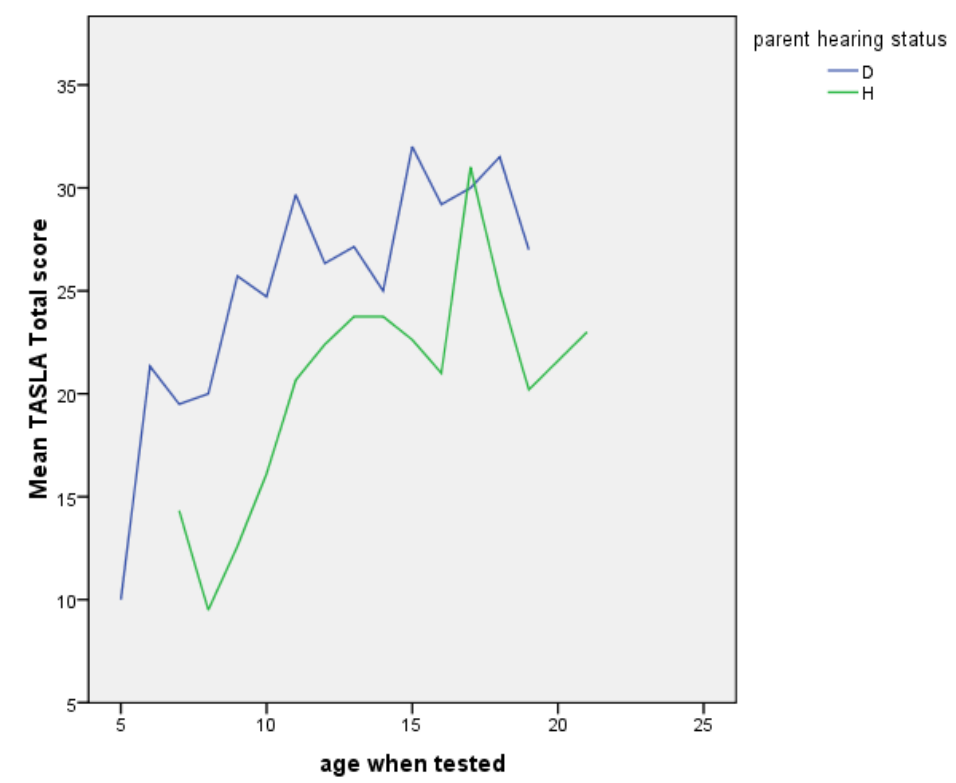

Figure 2: Mean TASLA-R Scores, Age in Years When Tested and Hearing Status of Parents $(\mathrm{n}=140)$.

A t-test was used with parent hearing status as between groups variable and TASLA-R total score as the dependent measure. The between groups variable was significant was significant: $t(2,136)=5.248, \mathrm{p}<.05$.

A one-way ANOVA was used to test the differences in TASLA-R scores among the three grade levels. Grade level performance differed significantly across the three grade levels (elementary, junior high and high school): $\mathrm{F}(2,137)=$ $22.640, \mathrm{p}<.05$. Tukey post-hoc comparisons of the three groups indicated that the high school level $(\mathrm{M}=26.31,95 \%$ CI $[24.63,28.00])$ scored significantly higher on the TASLA-R than the Elementary level group $(\mathrm{M}=18.30,95 \% \mathrm{CI}$ $[16.21,20.40]), \mathrm{p}<.05$. Comparisons between the junior high group and the high school were not significantly different.

TABLE 6:

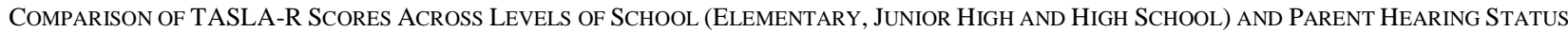
(DEAF VS HEARING)

\begin{tabular}{llll}
\hline School Levels & Mean & N & $\begin{array}{c}\text { Standard } \\
\text { Deviation }\end{array}$ \\
\hline Deaf Parents & & & 5.768 \\
Elementary & & 23 & 4.501 \\
Junior High & 21.91 & 19 & 3.011 \\
High School & 26.53 & 20 & 5.86 \\
Total & 30.70 & 62 & 5.480 \\
Hearing Parents & 26.16 & & 4.673 \\
Elementary & & 20 & 5.750 \\
Junior High & 14.15 & 27 & 6.605 \\
High School & 22.93 & 31 & \\
Total & 23.48 & 78 & \\
Total & 20.90 & & \\
Elementary & & 43 & \\
Junior High & 18.30 & 4.809 \\
High School & 24.41 & 46 & 5.83 \\
Total & 26.31 & 51 & 6.793 \\
\hline
\end{tabular}




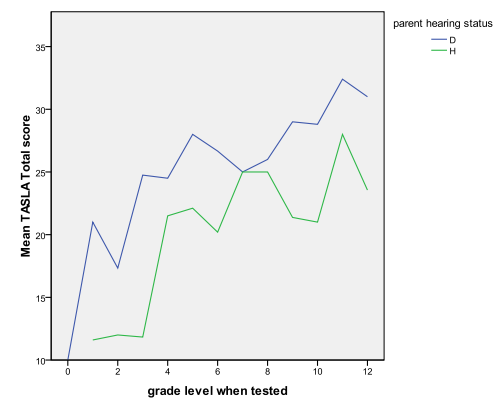

Figure 3: Comparison of TASLA-R Scores Across Levels of School (K to $12^{\text {th }}$ grade) Elementary, and Parent Hearing Status $($ Deaf Vs Hearing) $(\mathrm{n}=$ 140)

Research Question \#2: Does a relationship exist between students' background variables and metalinguistic abilities?

Researchers have pointed out the importance of describing the background variables of deaf students because many of these characteristics such as age of onset, degree of hearing loss, age, non-verbal IQ will have an effect on deaf children's language learning. To this end, efforts were made to give a comprehensive description of the background variables of the 140 children in this study. See tables 1,2 and 3 above.

\section{Student Background Characteristics}

Correlation analyses were performed using the TASLA-R scores as the dependent measure and the predictor variables coded as categorical data: ethnicity, gender, educational placement, geographic location, mother sign skill, and etiology.

A Spearman Rho correlation was computed to assess the relationship between TASLA-R total scores and the six categorical variables: ethnicity, gender, educational placement, school, mother's signing skill, and etiology. There was a correlation between the variables TASLA-R scores and Ethnicity $[\mathrm{r}=.256, \mathrm{n}=140, \mathrm{p}<.01]$ and Mother signing skills $[\mathrm{r}=.307, \mathrm{n}=140, \mathrm{p}<.01]$. No relationships were found between other background variables: gender, educational placement, school, etiology and secondary disabilities.

Since a relationship was found between ethnicity and TASLA-R scores and mother signing skill and TASLA-R scores, two additional one-way ANOVAs were carried out.

First, a one-way ANOVA was used to test for differences among the ethnic groups. See table 7.

TABLE 7:

TASLA-R TOTAL SCORES AND ETHNICITY GROUPINGS

\begin{tabular}{lccl}
\hline $\begin{array}{l}\text { Ethnicity } \\
\text { Groupings }\end{array}$ & Mean & $\mathbf{N}$ & $\begin{array}{l}\text { Standard } \\
\text { Deviation }\end{array}$ \\
\hline White & & & 6.637 \\
African-Am & 24.30 & 98 & 5.901 \\
Asian-Am & 21.41 & 22 & 4.243 \\
Hispanic-Am & 13.00 & 16 & 6.577 \\
Biracial & 22.06 & 2 & 2.121 \\
& 10.50 & & \\
Total & 23.23 & 140 & 6.793 \\
\hline
\end{tabular}

Differences in group performances on the TASLA-R differed across ethnic groups: $\mathrm{F}(4,135)=4.398, \mathrm{p}<.05$. Tukey's post-hoc comparisons of the five groups indicated that the White group $(\mathrm{M}=24.30,95 \%$ CI [22.97, 25.63]) outperformed the biracial group $(M=10.50,95 \% \mathrm{CI}-8.56,29.56)$. The other groups were not statistically significant at $\mathrm{p}<.05$ level.

Secondly, another one-way ANOVA was used to test for differences among the teacher ratings of the mothers' sign skills. Performances on the TASLA-R differed across the different mothers' ratings of sign skills groups: $\mathrm{F}(4,129)=$ $6.435, \mathrm{p}<.05$. Tukey's post-hoc comparisons of the five sign rating groups indicated that outstanding sign skill group $(\mathrm{M}=25.50,95 \% \mathrm{CI}[23.94,27.06])$ outperformed the other group rated poor signer $(\mathrm{M}=18.41,95 \% \mathrm{CI}[15.84,20.98])$ The other groups were not statistically significant at $\mathrm{p}<.05$ level. See table 8 .

TABLE 8:

TASLA-R TOTAL SCORES AND MOTHER's SIGN SKILL (AS RATED BY TEACHERS) (N=132)

\begin{tabular}{lccc}
\hline Mother Sign Skill & Mean & N & $\begin{array}{l}\text { Standard } \\
\text { Deviation }\end{array}$ \\
\hline Outstanding & 26.75 & 59 & 5.722 \\
Good & 23.48 & 25 & 6.752 \\
Fair & 23.64 & 14 & 5.786 \\
Poor & 18.25 & 28 & 6.824 \\
None & 25.83 & 6 & 5.845 \\
Total & 23.52 & 132 & 6.747 \\
\hline
\end{tabular}


A second multiple regression analysis was done with the TASLA-R as the dependent variable and the independent variable, coded as scaled variables: Pure Tone hearing loss in better ear and non-verbal IQ were coded as predictor variables. There was a correlation between the variables TASLA-R scores and IQ score was statistically significant $[\mathrm{r}$ $=.518, \mathrm{n}=94, \mathrm{p}<.05]$. There was no relationship between TASLA-R score and the Pure Tone Average hearing loss in the better ear.

In the second analysis, the researcher used the TASLA $-\mathrm{R}$ as a predictor to determine how much variance was contributed by non-verbal IQ, and the Pure Tone Average in Better Ear. Using the enter method, a significant model emerged $(\mathrm{F}(2,92)=16.827, \mathrm{p} .<.05$. Adjusted R square $=.252$. Thus, IQ variable accounted for $25 \%$ of the model. Significant variables are the following: For the Predictor variable, non-verbal IQ, Beta $=.497, \mathrm{p}<.01$. The Pure Tone Average Hearing Loss in better ear was not significant predictor in this model.

Research Question \#3: What is the relationship between ASL abilities and English- literacy achievement as measured by the three subtests of the SAT-9: reading vocabulary, reading comprehension and language subtests?

To address this question, the number of children who had SAT-9 scores for the three sub-tests: vocabulary, reading comprehension and language were examined. The Stanford Achievement Test $-9^{\text {th }}$ edition is a norm-referenced test for deaf students. The Stanford-9 published by Harcourt Brace Educational Measurement has these subtests normed on deaf students: reading vocabulary, reading comprehension, mathematics problem solving, mathematics procedures, spelling and language. Within these test content areas there are eight test levels that are vertically equated so that scores are reported on a single scale for each subtest. These "scaled scores" allow comparisons of scores from different test levels. Each test level was designed to measure curriculum content commonly taught to hearing students in specific grades. For instance, one can compare the scaled score of a student in third grade with another student in high school.

For purposes of this study, the three SAT-9 subtests: reading comprehension, reading vocabulary and language were utilized. The reading comprehension subtest consisted of 9 to 10 stories (short paragraphs of fiction, nonfiction, recipes, environmental signage) followed by 6 questions that assessed comprehension using literal and inferential kinds of questions. A multiple-choice format was used, with four possible answers that student could choose from. The reading vocabulary subtest consisted of 30 sentences with an underlined word and the student chose from four choices the word that best explained the underlined word. The language subtest consisted of approximately 30 items, also in multiplechoice format where the student was asked questions about punctuation, capitalization (mechanics of English) or word choice or word grammar such as filling in a noun or verb or adjective.

Of the 140 children who took the TASLA-R, these SAT-9 scores were available: Reading vocabulary $(\mathrm{n}=73)$, reading comprehension $(n=74)$ and language $(n=63)$. Using the TASLA-R score and each of the SAT-9 subtest scores, a Pearson Product Moment Correlation was computed to assess the relationship of the TASLA-R score and each of the three subtests.

The correctional was significant between the variables TASLA-R scores and Reading Vocabulary subtest scores [ $\mathrm{r}$ $=.491, \mathrm{n}=73, \mathrm{p}<.01]$ and Reading Comprehension $[\mathrm{r}=.582, \mathrm{n}=74, \mathrm{p}<.01]$ and Language $[\mathrm{r}=.402, \mathrm{n}=63, \mathrm{p}<.01]$.

A second analysis was carried out, a multiple regression analysis to determine how much variance the three English literacy subtests contributed to the TASLA -- R score. To this end, the researchers used the TASLA -- R as a predictor to determine how much variance was contributed by SAT Vocabulary, SAT Reading Comprehension and SAT Language. Using the enter method, a significant model emerged $(\mathrm{F}(3,58)=6.19$, p. $<.05$. Adjusted R square $=.204$. Significant variables are the following. For the Predictor variable, the reading comprehension subtest score was significant, Beta $=.765, \mathrm{p}<.01$. Reading vocabulary and the Language subtest scores were not significant predictors in this model.

\section{Summary of Findings}

The findings of this study are as follows:

1. As the children got older, their ASL metalinguistic awareness increased, as demonstrated on the TASLA-R, a 40item test designed for this study $(\mathrm{F}(13,137)=3.402, \mathrm{p}<.05)$.

2. On the TASLA-R, the deaf children of deaf parents group outperformed the deaf children of hearing group and this difference reached statistical significance: $\mathrm{t}(2,136)=5.248, \mathrm{p}<.05$.

3. Deaf students in high school outperformed deaf children in elementary and junior high on the TASLA-R. Grade level performance differed significantly across the three grade levels (elementary, junior high and high school): $\mathrm{F}$ (2, $137)=22.640, \mathrm{p}<.05$. Tukey post-hoc comparisons of the three groups indicated that the high school level $(\mathrm{M}=26.31$, $95 \%$ CI $[24.63,28.00])$ scored significantly higher on the TASLA-R than the Elementary level group $(\mathrm{M}=18.30,95 \%$ CI $[16.21,20.40]), \mathrm{p}<.05$. Comparisons between the junior high group and the high school were not significant.

4. There was a statistically significant correlation between the variables TASLA-R scores and ethnicity $[r=.256, \mathrm{n}=$ $140, \mathrm{p}<.01]$ and mother signing skills $[\mathrm{r}=.307, \mathrm{n}=140, \mathrm{p}<.01]$. Caucasians performed better and students with mothers who had more signing skills also performed better on the TASLA-R. No relationships were found between other background variables: gender, educational placement (residential only vs. day school + residential school), school, etiology and secondary disabilities. Differences in group performances on the TASLA-R differed across the ethnic groups: $\mathrm{F}(4,135)=4.398, \mathrm{p}<.05$. Tukey's post-hoc comparisons of the five groups indicated that the White group $(\mathrm{M}=24.30,95 \% \mathrm{CI}[22.97,25.63])$ outperformed the biracial group $(\mathrm{M}=10.50,95 \% \mathrm{CI}-8.56,29.56)$. The other groups were not statistically significant at $\mathrm{p}<.05$ level. 
5. Performances on the TASLA-R differed across the different mothers' ratings of sign skills groups: $\mathrm{F}(4,129)=$ $6.435, \mathrm{p}<.05$. Tukey's post-hoc comparisons of the five sign rating groups indicated that outstanding sign skill group $(\mathrm{M}=25.50,95 \% \mathrm{CI}[23.94,27.06])$ outperformed the other group rated poor signer $(\mathrm{M}=18.41,95 \% \mathrm{CI}[15.84,20.98])$. The other groups were not statistically significant at $\mathrm{p}<.05$ level.

6. Children with higher IQs scored higher than those with lower IQs $[\mathrm{r}=.518, \mathrm{n}=94, \mathrm{p}<.05]$. There was no relationship between TASLA-R score and the Pure Tone Average hearing loss in the better ear.

7. Using the enter method, a significant model emerged $(\mathrm{F}(2,92)=16.827$, p. $<.05$. Adjusted R square $=.252$. Thus, IQ variable accounted for $25 \%$ of the model. Significant variables are the following. For the Predictor variable, nonverbal IQ, Beta $=.497, \mathrm{p}<.01$. The Pure Tone Average Hearing Loss in better ear was not a significant predictor in this model.

8. Using the TASLA-R score and each of the SAT-9 subtest scores, a Pearson Product Moment Correlation was computed to assess the relationship of the TASLA-R score and each of the three subtests. The correctional was significant between the variables TASLA-R scores and Reading Vocabulary subtest scores $[\mathrm{r}=.491, \mathrm{n}=73, \mathrm{p}<.01]$ and Reading Comprehension $[\mathrm{r}=.582, \mathrm{n}=74, \mathrm{p}<.01]$ and Language $[\mathrm{r}=.402, \mathrm{n}=63, \mathrm{p}<.01]$.

9. The TASLA $-\mathrm{R}$ was used as the criterion, to determine how much variance was contributed by the predictors: the SAT Vocabulary, SAT Reading Comprehension and SAT Language. Using the enter method, a significant model emerged $(\mathrm{F}(3,58)=6.19$, p. $<.05$. Adjusted R square $=.204$. For the Predictor variable, Reading Comprehension subtest score was significant, Beta $=.765, \mathrm{p}<.01$. Reading vocabulary and the Language subtest scores were not significant predictors in this model.

\section{DISCUSSION AND RECOMMENDATIONS}

First, the TASLA-R needs to be administered to more children in order to further refine its psychometric properties. Secondly, on the whole, the older deaf children in this sample of 140 performed better on the TASLA-R than the younger members in the group, thus noting a developmental trend. That there were valleys and peaks along this development path suggests that there is some variability in deaf children achieving ASL metalinguistic awareness across the age groupings. The older deaf children were better able to judge whether a sign, a signed sentence or a signed discourse segment was correct or not than the younger children were. Clearly, these children received exposure to ASL from their deaf or hearing parents at home and from their deaf and hearing teachers who used ASL in their school environment and as they grew older, these skills increased.

The developmental progression as shown in this study has clinical importance as well. Clinicians working with ASLdelayed children can give them exposure to ASL stories and ask them questions about ASL structure. The structures in these 8 stories need to be further delineated (see Appendix 2) and added to the knowledge base of what we know about deaf children's ASL developmental milestones from birth to age five. From this list of developmental ASL structures, ASL standards and curriculum can be built.

Thirdly, the authors hypothesize that the use of whole stories to elicit student responses in making the correct judgments about sign correctness facilitated the students' ability to make metalinguistic judgments because it provided more context than a single sign or single signed sentence. Future studies that make the use of whole stories in the development of ASL assessments, rather than using only single sentences in order to tap deaf children's ability to attend to sign structure with the context of more ASL are recommended.

Fourth, while the three subtests-reading vocabulary, reading comprehension and language were significantly correlated to the TASLA-R scores, they were only moderately correlated. However when a multiple regression model was used, the subtest reading comprehension was found to predict TASLA-R scores. This finding needs to be further explored, as it concurs with studies showing a relationship between ASL proficiency and reading comprehension.

Future studies need to address this relationship between ASL proficiency and English reading comprehension. We still do not know the full extent how ASL supports reading comprehension. Do deaf children need a certain threshold of ASL skills and English skills before their bilingual transfer abilities start to enter into their language learning of reading? If so, ASL metalinguistic awareness is a strong predictor of English reading skills, if one supports the hypothesis that the same psycholinguistic processing operations are used in both, then future studies need to examine the phenomenon of sign-to-print mapping within an ASL/English bilingual setting. Clearly, language intervention studies are needed to clarify how using ASL and fingerspelling can enhance English reading instruction.

Based on Bialystok's model of metalingusitic development (2001), metalinguistic skills have been defined as the ability to reflect upon language, to attend to its form and structure apart from its content or meaning, and to make judgments or evaluate its correctness or incorrectness. As such, metalinguistic skills give deaf students a cognitive and linguistic tool to think about and analyze their ASL skills. As children get older, their ability to think about their ASL language increases. In this study, we interpret our data to suggest that deaf children, as they get older, develop psycholinguistic processing operations that access their internalized grammar of ASL so they can attend to and make judgments about abstract representations of ASL. How deaf children can recruit these psycholinguistic processing operations and use their "ASL language template" to manipulate ASL representations and to map them onto the learning of their second language English remains to be studied in future studies. Evidence from correlation research with deaf adults suggests that such a relationship exists between ASL proficiency and English reading ability (Freel, 
Clark, Anderson, Gilbert, Musyoka \& Hauser, 2012; Ausbrooks, 2007; Delana, Gentry \& Andrews, 2007; GoldinMeadow \& Mayberry, 2001; see also reviews in Chamberlain, Morford, \& Mayberry, 2000). However, additional studies are needed to clarify the ASL and fingerspelling to English print relationship at the reading comprehension and word analyses skill levels, test its usefulness and make it practical for the parents, pediatric audiologists and clinicians in early childhood education programs and K-12 programs. An instrument such as the TASLA-R can facilitate these efforts.

Appendix 1. The ASL Structures PRESENTED In the Total TASLA - R

\begin{tabular}{|c|c|c|}
\hline Story Title and Test Item & Linguistic Area & Comprehension based on Reception of ASL Structure \\
\hline $\begin{array}{l}\text { Practice Warm-Up Story } \\
\text { Not Meant To Be } \\
1\end{array}$ & Phonology & Identify handshape of sign \\
\hline 2 & Morphology & Identify Noun-verb pairs \\
\hline 3 & Semantics & Recognition of object placement in hand \\
\hline 4 & Syntax & Using spatial memory using three areas in space \\
\hline 5 & Pragmatics & Use of role shifting to identify signer \\
\hline \multicolumn{3}{|l|}{ Deaf Tree } \\
\hline 1 & Phonology & $\begin{array}{l}\text { Identify the group of signs which do not share the " } 5 \text { " } \\
\text { handshape }\end{array}$ \\
\hline 2. & Morphology & Identify how to make a plural (reduplication) \\
\hline 3 & Semantics & $\begin{array}{l}\text { Identify the meaning of the sign "Y" handshape that circles near } \\
\text { the nose. }\end{array}$ \\
\hline 4 & Syntax & $\begin{array}{l}\text { Identify the subject and the indirect object using spatial location } \\
\text { and direction }\end{array}$ \\
\hline 5 & Pragmatics & $\begin{array}{l}\text { Identify role shifting with two characters and identifying the } \\
\text { perspective of each. }\end{array}$ \\
\hline \multicolumn{3}{|r|}{ PotP } \\
\hline 6 & Phonology & $\begin{array}{l}\text { Identify the sign made using the four parameters correctly } \\
\text { (handshape, location, movement, a palm orientation) }\end{array}$ \\
\hline 7 & Morphology & Identify the meaning of the Non-manual signal (NMS) "ooo" \\
\hline 8 & Semantics & Identify the meaning of the sign using appropriate classifiers \\
\hline 9 & Syntax & Identify Past Tense in a sentence \\
\hline 10 & Pragmatics & Identify role shifting with two characters planning an action. \\
\hline \multicolumn{3}{|l|}{ Pagers for Sale } \\
\hline 11 & Phonology & Identify the NMS "thh" when incorporated in a single sign \\
\hline 12 & Morphology & Identify the meaning of the NMS (Non-manual signal) "cha" \\
\hline 13 & Semantics & $\begin{array}{l}\text { Identify the meaning of the sign (handshape: X) across the } \\
\text { object. }\end{array}$ \\
\hline 14 & Syntax & Identify possessive pronoun in signed sentence. \\
\hline 15 & Pragmatics & Identify spatial arrangement of property \\
\hline \multicolumn{3}{|l|}{ Deaflympics } \\
\hline 16 & Phonology & $\begin{array}{l}\text { From } 4 \text { groups of } 3 \text { lexical signs, identify which group of signs } \\
\text { has similar parameters (handshape, movement and location) to } \\
\text { the single lexical sign provided. }\end{array}$ \\
\hline 17 & Morphology & Identify on-surface morpheme classifier handshape \\
\hline 18 & Semantic & Identify meaning of the classifier \\
\hline 19 & Syntax & Identify the correct sequence in several signed sentences. \\
\hline 20 & Pragmatics & Identify the correct topic signed in beginning of the story. \\
\hline \multicolumn{3}{|l|}{ The Haunted House } \\
\hline 21 & Phonology & $\begin{array}{l}\text { From } 4 \text { groups of } 3 \text { lexical signs, identify which group has the } \\
\text { same handshape, location, and palm-orientation of the sample } \\
\text { lexical sign presented. }\end{array}$ \\
\hline 22 & Morphology & $\begin{array}{l}\text { Identify which group of noun-verb pairs is not similar to the } \\
\text { sample noun-verb pair provided. }\end{array}$ \\
\hline 23 & Semantics & Identify the meaning of the sample sign given. \\
\hline 24 & Syntax & Identify verb agreement with shifting reference (spatial syntax) \\
\hline 25 & Pragmatics & $\begin{array}{l}\text { Identify the character in front of the storyteller (first person vs. } \\
\text { third person) }\end{array}$ \\
\hline \multicolumn{3}{|l|}{ Three Deaf Indians } \\
\hline 26 & Phonology & $\begin{array}{l}\text { Identify the correct group of } 3 \text { lexical signs that has the same } \\
\text { parameter location as the sample lexical sign provided. }\end{array}$ \\
\hline 27 & Morphology & $\begin{array}{l}\text { Identify the correct use of number incorporation, classifier } \\
\text { predicates and movements that correspond to the storyline. }\end{array}$ \\
\hline 28 & Semantics & $\begin{array}{l}\text { Identify the correct meaning of the on surface morpheme with } \\
\text { movement. }\end{array}$ \\
\hline 29 & Syntax & $\begin{array}{l}\text { Identify the topic/comment structure and facial grammar used } \\
\text { correctly in the signed sentences. }\end{array}$ \\
\hline 30 & Pragmatics & Identify turn-taking in discourse \\
\hline
\end{tabular}




\begin{tabular}{|l|l|l|}
\hline The Golden Crown & & \\
\hline 31. & Phonology & $\begin{array}{l}\text { Identify which item is not an example of lexicalized } \\
\text { fingerspelling }\end{array}$ \\
\hline 32 & Morphology & $\begin{array}{l}\text { Identify which sign pairs follows the rule: reduplication by } \\
\text { movement }\end{array}$ \\
\hline 33 & Semantics & $\begin{array}{l}\text { Identify the meaning in the group of 2 pictures that use the } \\
\text { appropriate descriptive classifiers }\end{array}$ \\
\hline 34 & Syntax & Identify the correct directionality in the signed sentences \\
\hline 35 & Pragmatics & Identify the correct signer in a discourse conversation \\
\hline Heartbeat & Phonology & $\begin{array}{l}\text { Identify the incorrect classifier handshape from the following } \\
\text { list of ASL lexical signs }\end{array}$ \\
\hline 36 & Morphology & $\begin{array}{l}\text { Identify the incorrect classifier predicate and signer perspective } \\
\text { from the list of ASL phrases }\end{array}$ \\
\hline 37 & Identify the correct meaning of the signs \\
\hline 38 & Semantics & Identify the incorrect signed sentence structure. \\
\hline 39 & Pyntax & Identify the discourse structure (poetic device) used in this poem \\
\hline 40 &
\end{tabular}

APPENDiX 2. ITEM IDENTIFICATION By ASL Syntactic STRUCTURE FOR THE TASLA - R

\begin{tabular}{|l|l|}
\hline ASL Linguistic Structures & TASLA-R Item number \\
\hline PHONOLOGY & $1,6,11,16,21,26,31,36$ \\
\hline MORPHOLOGY & $2,7,12,17,22,27,32,37$ \\
\hline SEMANTICS & $3,8,13,18,23,28,33,38$ \\
\hline SYNTAX & $4,9,14,19,24,29,34,39$ \\
\hline PRAGMATICS & $5,10,15,20,25,30,35,40$ \\
\hline
\end{tabular}

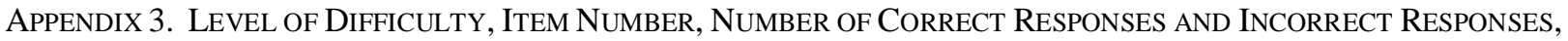
NAME OF STORY, AND TYPE OF ASL STRUCTURE FOR THE TASLA - R

\begin{tabular}{|c|c|c|c|c|c|}
\hline $\begin{array}{l}\text { Rank Order of } \\
\text { Level of Difficulty } \\
\text { (from MOST } \\
\text { DIFFICULT item } \\
\text { (1) to EASIEST } \\
\text { item (34) } \\
\end{array}$ & $\begin{array}{l}\text { Test } \\
\text { Item \# }\end{array}$ & $\begin{array}{l}\text { \# Correct Responses } \\
\text { by Students } \\
\text { (total students } \\
\text { taking the TASLA- } \\
\mathrm{R}, \mathbf{n}=140 \text { ) }\end{array}$ & $\begin{array}{l}\text { \# Incorrect } \\
\text { Responses by } \\
\text { students }\end{array}$ & Story Title & ASL Structure \\
\hline 1 & 16 & 28 & 105 & Deaflymics & Phonology \\
\hline 2 & 21 & 30 & 103 & The Haunted House & Phonology \\
\hline 3 & 11 & 34 & 106 & Pagers for Sale & Phonology \\
\hline 4 & 32 & 30 & 93 & The Golden Crown & Morphology \\
\hline 5 & 24 & 36 & 97 & The Haunted House & Syntax \\
\hline 6 & 33 & 34 & 89 & The Golden Crown & Semantics \\
\hline 7 & 29 & 43 & 90 & Three Deaf Indians & Syntax \\
\hline 8 & 30 & 46 & 87 & Three Deaf Indians & Pragmatics \\
\hline 9 & 22 & 51 & 82 & The Haunted House & Morphology \\
\hline 10 & 39 & 50 & 73 & Heartbeat & Syntax \\
\hline 11 & 40 & 57 & 66 & Heartbeat & Pragmatics \\
\hline 12 & 25 & 75 & 58 & The Haunted House & Pragmatics \\
\hline 13 & 37 & 61 & 62 & Heartbeat & Morphology \\
\hline 14 & 27 & 92 & 41 & Three Deaf Indians & Morphology \\
\hline 15 & $\begin{array}{l}38 \\
7\end{array}$ & $\begin{array}{l}74 \\
82\end{array}$ & $\begin{array}{l}49 \\
58\end{array}$ & $\begin{array}{l}\text { Heartbeat } \\
\text { Snake Flies }\end{array}$ & $\begin{array}{l}\text { Semantics } \\
\text { Morphology }\end{array}$ \\
\hline 16 & $\begin{array}{l}15 \\
26\end{array}$ & $\begin{array}{l}82 \\
88 \\
\end{array}$ & $\begin{array}{l}58 \\
44\end{array}$ & $\begin{array}{l}\text { Pagers for Sale } \\
\text { Three Deaf Indians }\end{array}$ & $\begin{array}{l}\text { Pragmatics } \\
\text { Phonology }\end{array}$ \\
\hline 17 & $\begin{array}{l}31 \\
20\end{array}$ & $\begin{array}{l}74 \\
82\end{array}$ & $\begin{array}{l}49 \\
51\end{array}$ & $\begin{array}{l}\text { The Golden Crown } \\
\text { Deaflympics }\end{array}$ & $\begin{array}{l}\text { Phonology } \\
\text { Pragmatics }\end{array}$ \\
\hline 18 & 34 & 76 & 62 & The Golden Crown & Syntax \\
\hline 19 & 6 & 95 & 45 & Snake Flies & Phonology \\
\hline 20 & 35 & 84 & 39 & The Golden Crown & Pragmatics \\
\hline 21 & 4 & 87 & 53 & The Deaf Tree & Syntax \\
\hline 22 & 12 & 100 & 40 & Pagers for Sale & Morphology \\
\hline 23 & 1 & 120 & 20 & The Deaf Tree & Phonology \\
\hline 24 & 10 & 106 & 34 & Snake Flies & Pragmatics \\
\hline 25 & $\begin{array}{l}19 \\
28\end{array}$ & $\begin{array}{l}106 \\
107\end{array}$ & $\begin{array}{l}27 \\
26\end{array}$ & $\begin{array}{l}\text { Deaflympics } \\
\text { Three Deaf Indians }\end{array}$ & $\begin{array}{l}\text { Syntax } \\
\text { Phonology }\end{array}$ \\
\hline 26 & 8 & 112 & 28 & Snake Flies & Semantics \\
\hline 27 & 5 & 111 & 29 & The Deaf Tree & Pragmatics \\
\hline 28 & 3 & 111 & 29 & The Deaf Tree & Semantics \\
\hline
\end{tabular}




\begin{tabular}{|l|l|l|l|l|l|}
\hline 29 & 2 & 120 & 20 & The Deaf Tree & $\begin{array}{l}\text { Morphology } \\
\text { Phonology }\end{array}$ \\
\hline 30 & 36 & 105 & 85 & Pagers for Sale & Semantics \\
\hline 31 & 13 & 118 & 22 & Pagers for Sale & Syntax \\
\hline 32 & 14 & 109 & 31 & Deaflympics & Semantics \\
\hline 33 & 18 & 121 & 12 & The Haunted House & Semantics \\
\hline 34 & 23 & 126 & 7 & Deaflympics & Syntax \\
\hline & 17 & 125 & 8 & & syntax \\
\hline
\end{tabular}

\section{REFERENCES}

[1] Adams. M. (1990). Beginning to read: Thinking and learning about print. Cambridge MA: MIT Press.

[2] Andrews, J. F., Leigh, I. W., \& Weiner, M. T. (2004). Deaf people: Evolving perspectives from psychology, education and sociology. Boston: Allyn and Bacon.

[3] Andrews, J. \& Rusher, M. (2010). Codeswitching Techniques: Evidence-Based Instructional Practices for the ASL/English Bilingual Classroom. American Annals of the Deaf, 155(4), 407-424.

[4] Ausbrooks, M. (2007). Predictors of reading success among deaf bilinguals: Examining the relationship between ASL proficiency and English. Unpublished doctoral dissertation, Lamar University, Beaumont, TX.

[5] Ausbrooks-Rusher, M., Schimmel \& Edwards, S. (2012). Utilizing Fairview as a Bilingual Response to Intervention (RTI): Comprehensive Curriculum Review with Supporting Data. Theory and Practice in Language Studies 2(7), 1317-1329.

[6] Baker, S. (2010, July). The Importance of Fingerspelling for Reading. Visual Language and Visual Learning Science of Learning Center. (Research Brief No. 1). Washington, D.C.

[7] Berko-Gleason, J. (1997). The Development of Language. Fourth edition, Boston, MA: Allyn \& Bacon.

[8] Bialystok, E. (2001). Bilingualism in Development: Language, Literacy \& Cognition. New York: Cambridge University Press.

[9] Bialystok, E. (1991). Language Processing in Bilingual Children. New York: Cambridge University Press.

[10] Cairns, H., Schlisselberg, G., Waltzman, D. \& McDaniel, D. (2006). Development of a Metalinguistic Skill: Judging the Grammaticality of Sentences. Communication Disorders Quarterly, 27(4), 213-220.

[11] Chamberlain, C., Morford, J., \& Mayberry, R. (Eds.). (2000). Language acquisition by eye. Mahwah, NJ: Lawrence Erlbaum.

[12] Delana, M., Gentry, M. \& Andrews, J. (1997). The efficacy of ASL/English bilingual education: Considering Public Schools. American Annals of the Deaf, 152(1), 73-87.

[13] Diaz, R. M. and Klingler, C. (1991). Towards an explanatory model of the interaction between bilingualism and cognitive development. NY: Longman. In: Bialystock, E. Language Processing in bilingual children, pp. 167-192. New York: Cambridge University Press.

[14] Freel, B., Clark, M., Anderson, M., Gilbert, G., Musyoka, M. \& Hauser, P. (.2010). Deaf Individuals' Bilingual Abilities: ASL Proficiency, Reading Skill and Family Characteristics. Psychology, 2011, 2(1), 18-23.

[15] French, M. M. (1999). Starting with assessment: A developmental approach to deaf children's literacy. Washington, DC: Gallaudet University Pre-College National Mission Programs.

[16] Goldin-Meadow, S., \& Mayberry, R. (2001). How do profoundly deaf children learn to read? Learning Disabilities Research and Practice, 16(4), 222-229.

[17] Gonzales, H., Covell, J. \& Andrews, J. (2005). Language Acquisition: Where is the Sign Language Assessment on my son's IEP? Endeavor, Vol. 2, pp. 18-19, 20-21.

[18] Gronlund, N. (1981). Measurement and evaluation in teaching. New York: Macmillan.

[19] Grojean, F. (2008). Studying Bilingualism. New York: Oxford University Press.

[20] Grosjean, F. (2010). Bilingual: Life and Reality. Boston, MA: Harvard University Press.

[21] Haotinstall-Nykaza, T. \& Schick, B. (2007). The Transition from Fingerspelling to English Print: Facilitating English Decoding. Journal of Deaf Studies and Deaf Education, 12(2), 172-183.

[22] Haug, T. (1999). Review of Signed Language Assessments Instruments. Retrieved March 13, 2011, http://www.sign-lang.unihamburg.de/intersign/workshop4/haug.html.

[23] Klima, E. \& Bellugi, U. (1979). The Signs of Language. Cambridge, MA: Harvard University Press.

[24] Mayer. C. \& Wells, D/. (1996). Can the Linguistic Interdependence Theory Support a Bilingual-Bicultural Model of Literacy Instruction for Deaf Students. Journal of Deaf Studies and Deaf Education, 1(2), 93-107.

[25] Menendez, B. (2010). Cross-modal bilingualism: contact as evidence of linguistic transfer in sign bilingual education. International Journal of Bilingual Education and Bilingualism, 13(2), 201-223.

[26] Peters, C. (2000). Deaf American Literature: From Carnival to Canon. Washington, D.C.: Gallaudet University Press.

[27] Poizner, H., Klima, E., \& Bellugi, U. (2000). What the hands reveal about the brain. Cambridge, MA: MIT Press.

[28] Quigley, S. \& Kretchmer, R. (1982). The education of deaf children: Issues, theory, and practice. Baltimore University Park Press.

[29] Smith, A.K. The Performance of Deaf Students on a Test of American Sign Language Abilities-Receptive (TASLA-R). (2007). Unpublished doctoral dissertation, Lamar University, Beaumont, TX.

[30] Snow, C. (1990). The development of definitional skill. Journal of Child Language, 17, 677-710.

[31] Stanford Achievement Test 9th Edition for Hearing Impaired. (1996). New York: Harcourt Brace \& Company.

[32] Trezek, B., Wang, Y. \& Paul, P. (2010). Reading and Deafness: Theory, Research \& Practice. Cengage Learning.

[33] Valli, C. \& Lucas, C. (2000). Linguistics of American Sign Language: An introduction. Washington, DC: Gallaudet University Press. 
Adonia K. Smith has taught workshops and classes in Literacy, bilingual-bicultural methods, ASL, Deaf studies, ASL literature, ASL assessments at schools for the deaf, public schools and colleges/universities. She also has supervised and prepared teachers of deaf learners and has developed curricula and assessments for deaf learners. Dr. Smith is the vice-president of ASL Rose, a company that develops materials for deaf individuals and ASL learners.

Jean F. Andrews is professor of Deaf Studies/Deaf Education at Lamar University where she teaches in the graduate program and conducts applied research in language and literacy with deaf adults, children and youths and children in early childhood. She is a Texas certified teacher of the deaf and a Texas certified reading specialist.

Melissa Ausbrooks is the Director of Research at the Mississippi School for the Deaf in Jackson, Mississippi. She has been a classroom reading teacher, trained teachers of the deaf and trained educational leaders. She conducts applied research in ASL/English bilingualism for deaf children, youth and adults.

Mary Anne Gentry is professor at Lamar University and currently serves as the Director of the Masters Degree Program in Deaf Studies/Deaf Education. She has been training K-12 teachers in Deaf Education for the past 12 years. She also has 23 years of experience teaching elementary Deaf students. She is a Texas certified teacher of the deaf.

E. Lynn Jacobowitz is a teacher, researcher, scholar, and a performer. She has taught ASL, Deaf studies, ASL literature, and ASL curriculum/instruction for many years at Gallaudet University. She is the co-owner and president of ASL Rose, a company that develops Deaf-centered, Deaf-friendly materials for Deaf and hearing learners from Pre-K through college. 